\title{
AN EVALUATION OF THE STRESS PATTERN DISTRIBUTION FOR ORTHODONTIC TOOTH MOVEMENTS - A FINITE ELEMENT STUDY
}

Sameer Gupta ${ }^{1}$, Garima Gupta ${ }^{2}$, Manisha Sharma ${ }^{3}$, Pooja Sharma ${ }^{4}$, Sachin Goyal ${ }^{5}$, Pradeep kumar ${ }^{6}$

${ }^{1}$ Reader, Department of Orthodontics, Kanti Devi Dental College, Uttar Pradesh, India

${ }^{2}$ Reader, Department of Orthodontics, Kanti Devi Dental College, Uttar Pradesh, India

${ }^{3}$ Sr. Lecturer, Department of Oral \& Maxillofacial Pathology, Kanti Devi Dental College, Uttar Pradesh, India

${ }^{4}$ Sr. Lecturer, Department of Orthodontics, Kanti Devi Dental College, Uttar Pradesh, India

${ }^{5}$ Reader, Department of Periodontology, Bhojia Dental College, Himachal Pradesh, India

${ }^{6}$ PG Student, Department of Orthodontics, Kanti Devi Dental College, Uttar Pradesh, India

\begin{abstract}
|l
Objectives: This study was conducted to evaluate stress pattern distribution in the periodontal ligament during various orthodontic tooth movements. Methods: A 3 dimensional FEM model of upper central incisor was developed from C.T scan images of the skull excluding the mandible. The principal stress obtained on the periodontal ligament due to various orthodontic loadings (tipping, bodily movement, intrusion, extrusion and rotations) were tested. Results: Intrusion, extrusion and rotation produced stresses concentrated at apex of root. Bodily movement and tipping forces produce stress concentrated at the alveolar crest and not at the root apex. Conclusion: Clinical implications of this study suggests that if the clinician is concerned about placing heavy stresses on the root apex then vertical and rotational forces must be applied with caution.
\end{abstract}

Keywords : Finite Element Method, Mechanical Stress, Root Resorption

\section{INTRODUCTION}

The application of external forces to the teeth to produce orthodontic tooth movement carries some calculated risk . The most concerned risk is irreversible root resorption. The type of orthodontic tooth movement that have been reported to increase the risk of root resorption includes intrusion and tipping, as well as bodily movement into the lingual cortical plate of the maxilla. ${ }^{1}$

Different type of orthodontic tooth movement may produce different mechanical stress at varying location within the root. These stresses are important ramification in the study of orthodontic tooth movement and periodontal research because these stresses can be detrimental to periodontal health particularly in adult orthodontic patient. $^{2}$

In vivo measurement of stress is difficult at best thus, development of effective model or system is worthy goal.
Previously, resulting stresses within the periodontal ligament were studied with the use of both analytical and physical models like double exposure laser holographic interferometry, reflection studies, displacement transducer . $^{3-4}$

In the last decade the application of finite element method (FEM) has revolutionized dental biomechanical research. The technique has been described in detail in an early standard textbook by Zeinkiewicz. ${ }^{5}$

FEM is defined as a technique of discrediting a continuum into simple geometric shapes elements, enforcing material properties and governing relationship on these elements giving due consideration to loading and boundary conditions which results in set of equation, solution which gives the approximate behaviour of the continuum. FEM has many advantages over other methods highlighted by the ability to include heterogenicity of tooth material and irregularity of tooth contour. ${ }^{6}$ 
But still there is insufficient knowledge of the magnitude, direction \& distribution of the forces applied in orthodontic therapy \& also their effect on the tooth \& surrounding supporting structures. The purpose of this study is to evaluate distribution of stress pattern for various orthodontic tooth movement using a mathematical model of tooth with appropriate supporting structures, constructed by means of FEM.

Maxillary central incisor was chosen because it undergoes most detailed tooth movement and is at higher risk for root resorption than all other teeth except the maxillary lateral incisor. ${ }^{7}$

\section{MATERIAL \& METHODS}

\section{Finite Element Model:}

In this study FEM model of upper central incisor was developed from a dry humanskull excluding the mandible. Sequential CT scan images were made at the sliced thickness of $0.625 \mathrm{~mm}$ intervals in the axial and coronal direction, parallel to the Frankfort horizontal plane. The image section in CT were obtained in DICOM (Digital imaging and communication of medicine). This three dimensional data was reconstructed to give a three dimensional model using a software called Pro/ Engineer (Parametric technology corporation, USA).

Geometric surface were joined by the lines together. Each incremental layer created was compiled one above the other in axial and coronal direction and joined by lines. Lines were joined to create areas and thus the model of maxillary central incisor was created.

The geometric model was converted into the finite element model (Figure 1), the process known as

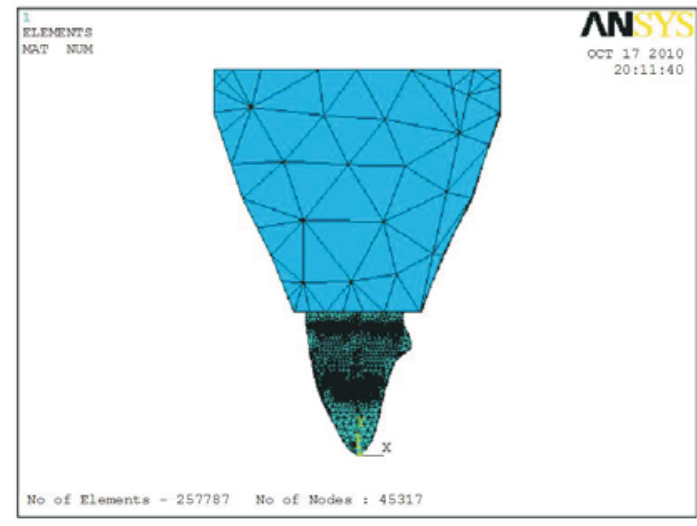

Figure 1: Finite element model of the tooth and supporting structure meshing. The complete geometry is defined as an assembly of discrete pieces called elements and is connected together at finite number of points called nodes. In the present study the model consisted of 45317 nodes and 257787 elements. Periodontal ligament was simulated $0.25 \mathrm{~mm}$ thick layer around the root.

Each structure was then assigned a specific material property. The different structures in the finite element model are enamel, dentine, periodontal ligament and alveolar bone. The material properties used in this study have been taken from finite element studies previously conducted. These material properties were the average values reported in the literature. ${ }^{8}$ (Table 1)

Table 1: Material Parameter's

\begin{tabular}{|l|c|c|}
\hline Material & $\begin{array}{c}\text { Young's modulus } \\
\left(\mathbf{N} / \mathbf{m m}^{2}\right)\end{array}$ & $\begin{array}{c}\text { Poisson's } \\
\text { Ratio }\end{array}$ \\
\hline Enamel & $8.41 \times 10^{4}$ & 0.33 \\
\hline Dentin & $1.83 \times 10^{4}$ & 0.30 \\
\hline Periodontal ligament & $6.90 \times 10^{-1}$ & 0.45 \\
\hline Bone & $1.37 \times 10^{4}$ & 0.30 \\
\hline
\end{tabular}

\section{Application Of Forces:}

The loading configuration was designed to simulate conventional orthodontic tooth movement. ${ }^{8}$ ( Table 2)

Table 2: Force System Applied

\begin{tabular}{|l|c|l|}
\hline $\begin{array}{l}\text { Force } \\
\text { Type }\end{array}$ & $\begin{array}{c}\text { Force } \\
\text { Magnitude } \\
\text { (gm) }\end{array}$ & Direction \\
\hline Intrusion & $25 \mathrm{gms}$ & $\begin{array}{l}\text { Intrusion force acting parallel to } \\
\text { the long axis of tooth at centre of } \\
\text { crown, which coincide with the } \\
\text { base of the bracket slot }\end{array}$ \\
\hline Extrusion & $25 \mathrm{gms}$ & $\begin{array}{l}\text { Extrusion force acting parallel to } \\
\text { long axis of tooth at centre of the } \\
\text { crown }\end{array}$ \\
\hline Rotation & $25 \mathrm{gms}$ & $\begin{array}{l}\text { Horizontal force along the line } \\
\text { angles of the incisor in opposite } \\
\text { directions at mid point }\end{array}$ \\
\hline Tipping & $25 \mathrm{gms}$ & $\begin{array}{l}\text { Horizontal force in a lingual } \\
\text { direction applied perpendicular } \\
\text { to long axis of the tooth at mid } \\
\text { point }\end{array}$ \\
\hline $\begin{array}{l}\text { Bodily } \\
\text { Movement }\end{array}$ & 25 gms & $\begin{array}{l}\text { Horizontal force in a lingual } \\
\text { direction with a couple in a } \\
\text { buccal crown direction at centre } \\
\text { of the crown }\end{array}$ \\
\hline
\end{tabular}

The sequential application of the above steps leads to a system of algebraic equations where the nodal displacements are unknown. These equations are solved by frontal solver technique present in the 
ANSYS software.

The resulting principle stress is evaluated and used to determine the pattern of stress distribution during various orthodontic movements. These stresses are expressed as compressive stress (which are negative) or tensile stress (which are positive).

\section{RESULTS}

\section{Intrusion}

When 25 gms of intrusive force was applied parallel to long axis of the tooth on the labial surface at the midpoint of the crown it produced compressive stress as high as $-0.0013 \mathrm{~N} / \mathrm{mm}^{2}$ near the apex of the PDL on labial side and tensile stress as high $0.0091 \mathrm{~N} / \mathrm{mm}^{2}$ at the cervical region on labial side \& apex on the lingual side (Figure 2).

The stress was found to be mainly concentrated at the apex. The stress found at the apical region was $0.0019 \mathrm{~N} / \mathrm{mm}^{2}$. It was mainly compressive in nature (Figure 2).

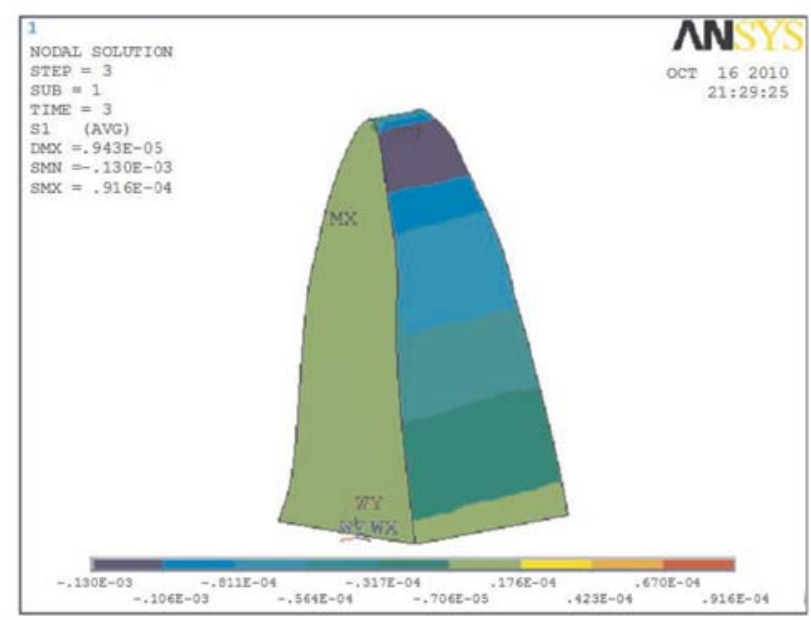

Figure 2: Stress distribution in PDL during intrusion

\section{Extrusion}

When 25gms of extrusive force was applied parallel to the long axis of the tooth on the labial surface at the midpoint of the crown it produces tensile stress as high as $0.0016 \mathrm{~N} / \mathrm{mm}^{2}$ near the apex of the PDL on labial side and compressive stress as high as $-0.0070 \mathrm{~N} / \mathrm{mm}^{2}$ is seen near the cervical margin on the labial side and apex on lingual side (Figure 3).

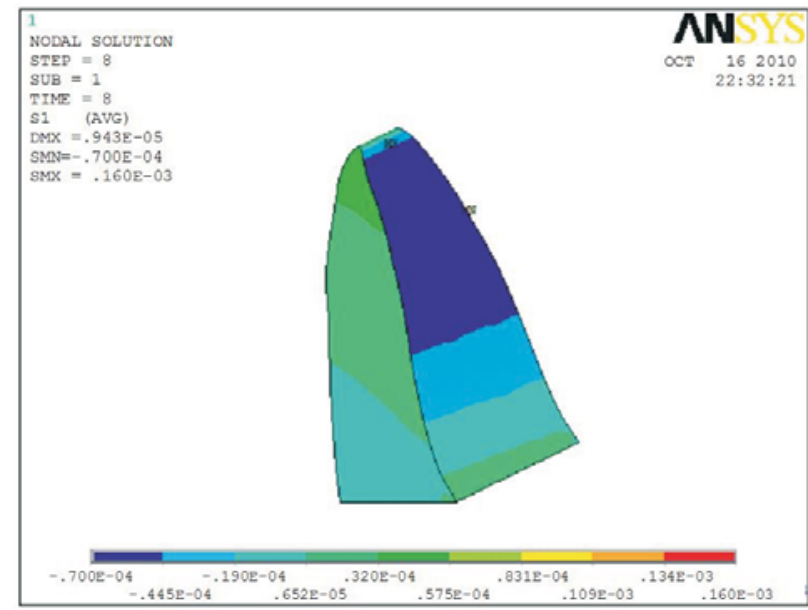

Figure 3: Stress distribution in PDL during extrusion

The stress was found to be mainly concentrated at the apical region. The stress at the apical region was $0.0018 \mathrm{~N} / \mathrm{mm}^{2}$. It was mainly tensile in nature (Figure $3)$.

\section{Rotation}

When $25 \mathrm{gms}$ of horizontally directed forces were applied in opposite directions along the line angles of the crown (Figure 4), the stress was distributed along the periodontal ligament with a general lack of any specific area of excessive stress. The compressive stress as high as $-0.0068 \mathrm{~N} / \mathrm{mm}^{2}$ was seen at the apical region and cervical margin. Tensile stress as high as $0.0081 \mathrm{~N} / \mathrm{mm} 2$ was seen at the apical region and cervical margin (Figure 4).

The apical region showed stress of $-0.0016 \mathrm{~N} / \mathrm{mm}^{2}$. It was mainly compressive in nature (Figure 4).

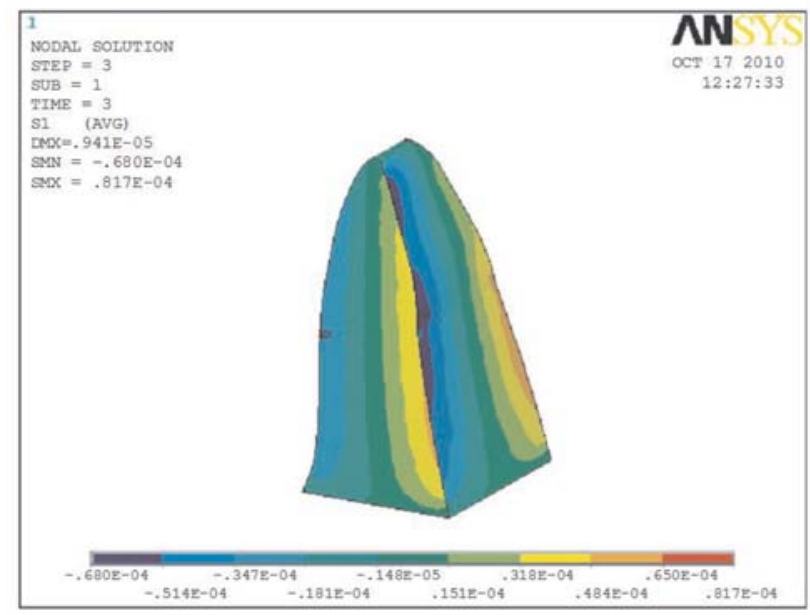

Figure 4: Stress distribution in PDL during rotation 


\section{Tipping}

When $25 \mathrm{gms}$ of tipping force was applied perpendicular to long axis of the teeth on the labial surface at the midpoint of the crown (Figure 5), it produced compressive stress as high as $-0.0064 \mathrm{~N} / \mathrm{mm}^{2}$ at the cervical margin on the lingual side and tensile stress was $0.0016 \mathrm{~N} / \mathrm{mm}^{2}$ at cervical margin on the labial side.

Stress at the apical region was found to be 0.00018 . It was tensile in nature (Figure 5).

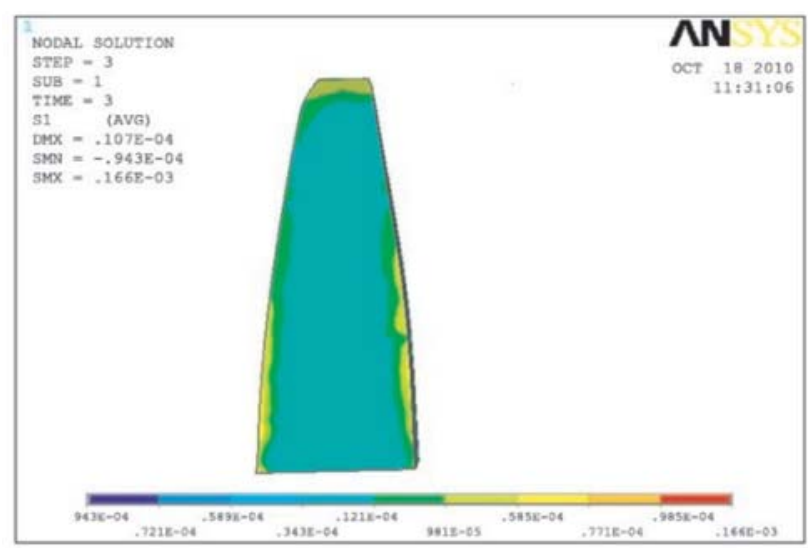

Figure 5 : Stress distribution in PDL during tipping

\section{Bodily Tooth Movement}

The compressive stress was found to be as 0.0083 $\mathrm{N} / \mathrm{mm}^{2}$ and was uniformly distributed on lingual side, and on labial side towards cervical region. Tensile stress along the labial side was found to be 0.0087 $\mathrm{N} / \mathrm{mm}^{2}$ and uniformly distributed but more towards cervical region.

These stresses were seen to be distributed uniformly throughout the PDL but stress concentration was found to be more at cervical region (Figure 6). The stress concentration at the apical region was found to be $0.00030 \mathrm{~N} / \mathrm{mm}^{2}$. It was compressive innature (Figure 6).

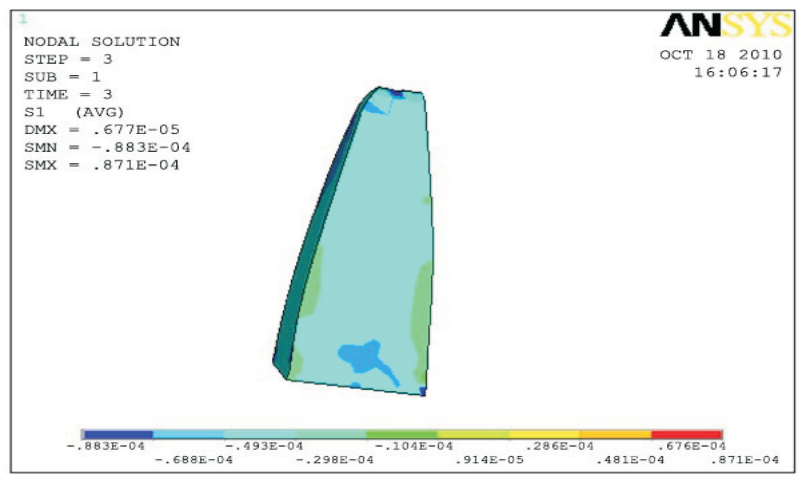

Figure 6 : Stress distribution in PDL during bodily movement

\section{DISCUSSION}

This study was undertaken to evaluate the stress pattern in the periodontal ligament during various orthodontic tooth movements on the crown surface of maxillary central incisor by means of the finite element method.

\section{Intrusion}

In the past, intrusive movement of the teeth has been considered difficult and most routine clinical vertical movement of teeth has been confined to extrusion .Attempts at intrusion may result in an increased incidence of root resorption and also in occasional devitalization. $^{?}$

In this present study intrusive stress was produced with the application of optimal intrusive forces of $25 \mathrm{gms}$ as proposed by Rudolph ${ }^{1}$ (Table 2).

The stress was found to be low, well below the optimal stress value of 150 and $250 \mathrm{~g} / \mathrm{cm}^{2}$ as suggested by Lee. ${ }^{11}$

In this study the stress was found to be mainly concentrated at the apex and it was compressive in nature. It was observed that area of periodontal ligament immediately adjacent to the point of force application comes under tensile stress (Figure 2). This may be due to the fact that the intrusive force was applied parallel to the long axis on the centre of clinical crown and not along the long axis.

These findings are in agreement with the study conducted by Wilson A.N et al. ${ }^{10}$ The stress profiles here were similar to other finite element studies conducted by, David Rudolph et $\mathrm{al}^{1}$, Allahar Geramy. ${ }^{12}$

\section{Extrusion}

In this present study extrusive stress was produced with the application of optimal extrusive forces of $25 \mathrm{gms}$ as proposed by Rudolph.1 (Table no. 2).The stress value was found to be within the optimal stress value suggested by Lee. ${ }^{12}$

In this study stress was found to be mainly concentrated at the apex. It was mainly tensile in nature. It was observed that area of periodontal ligament immediately adjacent to the point of force application comes under compressive stress (Figure 3). This maybe due to the fact that the extrusive force was applied parallel to the long axis on the centre of clinical crown and not along the long axis. These findings are 
in agreement with the study conducted by Wilson A.N et al. ${ }^{10}$

The stress profiles here were similar to other finite element studies conducted by, David Rudolph et al. ${ }^{1}$

The stress values and the stress pattern were not similar to those found by Wilson AN et $\mathrm{al}^{10}$ whose study shows maximum stress accumulation at cervical region of PDL i.e. $0.0046 \mathrm{~N} / \mathrm{mm}^{2}$, whilst the apical stress was $0.00205 \mathrm{~N} / \mathrm{mm}^{2}$. So the work of Wilson AN et al shows during extrusive movement maximum stress accumulation occurs at cervical region which contradict with results of the present study.

This difference may be attributed to the difference in type of tooth and magnitude of forces applied by Wilson AN et al. ${ }^{10}$

\section{Rotation}

In this study rotational stress was produced with the application of optimal rotational forces of $25 \mathrm{gms}$ along the line angles of the crown as proposed by Rudolph ${ }^{1}$ (Table 2). The stress values were found to be within the optimal stress value suggested by Lee. ${ }^{12}$

In this study the stress was mainly seen to be concentrated at the apex of the tooth. It was compressive in nature. During stress distribution lack of areas of high mechanical stress on the periodontal ligament was observed.

The stress pattern in this present study was found to be similar to the study conducted by David Rudolph et al. ${ }^{1}$

\section{Tipping}

Tipping is the simplest form of tooth movement. In this study tipping stresses were produced with the application of optimal labio-palatal tipping force of 25 gms as proposed by Rudolph ${ }^{1}$ (Table 2). In this present study stresses produced were found to be within the optimal stress values as suggested by Lee. ${ }^{12}$

In the present study when tipping force was applied it was found that stress was mainly concentrated at the cervical margin. At the cervical region compressive stress was seen on the lingual side and tensile stress on the labial side. This study also showed that most of the stresses were concentrated at the crest of the alveolar bone and not at the apex.

These stress patterns were found to be similar to other finite element studies conducted by David Rudolph et $\mathrm{al}^{1}, \mathrm{Mc}$ Guiness et $\mathrm{al}^{9}$, Allahyar Geramy. ${ }^{12}$

It will be noted that the stresses in periodontal ligament declines very rapidly as the apex is approached the consistently higher levels of stress found at the cervical margin suggest that this might be expected to be a frequent area of hyalinization during secondary tooth movement. ${ }^{9}$

\section{Bodily Movement}

In the present study a force of $25 \mathrm{gms}$ was applied at the centre of the clinical crown in labio-palatal direction. A counterbalancing force of $15.8 \mathrm{gms}$ was applied at the incisal tip in the palato-labial direction. So the net force applied was $9.2 \mathrm{gms}$ to move the tooth palatally.

The stresses were found to be evenly distributed throughout the length of the periodontal ligament but it was more concentrated at the alveolar crest. In the present study the stress produced was found to be below the optimal values suggested by Lee. ${ }^{12}$

The stress patterns and trends were found to be similar to the other finite element studies conducted by David Rudolph et al. ${ }^{1}$

Although stresses varied from cervix to apex, they were more constant than in tipping movements. These findings suggest that the translatory movements may be more physiologic, which was suggested in the previous histologic studies because of the lower and more uniform stress distribution in periodontal ligament .

\section{CONCLUSION}

On completion of the study, the following conclusions can be drawn from the findings of the present study:

1) The 3-dimentional FEM model is useful in analyzing the stress that occurs in and around a tooth in response to orthodontic forces.

2) The greatest amount of relative stress at the apex of maxillary central incisor occurred with Intrusion, Extrusion and Rotation.

3) Bodily movement and tipping forces produce stresses concentrated at the alveolar crest and not at the root apex.

Clinical implication of this study suggests that if the clinician is concerned about placing heavy stresses on the root apex, then vertical and rotational forces must be applied with caution . 
In the future it is anticipated that the finite element approach can be integrated with animal and clinical experiments to address key questions such as optimal stress and the relation of stress to tooth movement and bone remodelling. ${ }^{12}$

Finally it can be concluded that this tri-dimensional model is a useful example to investigate the biomechanism of dental movement, keeping in mind that it is more valid as a qualitative study.

\section{REFERENCES}

1) Rudolph DJ, Willes PMG, Sameshima GT. A finite element model of apical force distribution from orthodontic tooth movement.Angle Orthod 2001; 71(2):127-31.

2) Thilander B, Rygh $P$, Reitan $K$ Tissue reactions in orthodontics. In : Graber TM, Vanarsdall RL, Vig KWL, eds. Orthodontics : Current principles and techniques. 4th ed. St Louis , Mo: Elsevier Inc; 2005:174-78.

3) Mahesh Y, Ravidran NS, Balasubramanian MR. Holographic analysis of the initial canine displacement produced by four different retraction springs. Angle Orthod 2009; 00:368-72.

4) Choy K, Pae EK, Park Y, Kim KH, Burstone CJ. Effect of root and bone morphology on the stress distribution in periodontal ligament. Am J Orthod Dentofacial Orthop 2000; 117(1): 98105.

5) Jones ML, Hickman J, Middleton J, Knox J, Volp C. A validated finite element method study of orthodontic tooth movement in human subject. J Orthod 2001;28(1):29-38.
6) Rex S, Balasubramanian, Ravi K. Evaluation of apical force distribution for orthodontic tooth movements-a finite element analysis. JIOS 2010;44:38-42.

7) Sameshima GT, Sinclair PM, Predicting and preventing root resorption I: diagnostic factors. Am J Orthod Dentofacial Orthop 2001; 119:505-10.

8) Yoshida N, Jost-Brinkmann PG, Koga Y, Mimaki N, Kobayashi K. Experimental evaluation of initial tooth displacement, centre of resistance, and centre of rotation under the influence of an orthodontic force. Am J Orthod Dentofacial Orthop 2001; 120(2):190-197.

9) McGuinness NJ, Wilson AN, Jones ML, Middleton J. A stress analysis under periodontal ligament under various orthodontic loadings. Eur J Orthod 1991; 13(3):231-42.

10) Wilson AN, Middleton J, Jones ML, McGuinness NJ. The finite element analysis of stress in the periodontal ligament when subject to vertical orthodontic forces. Br J Orthod 1994; 21(2):161-7.

11) Geramy Allahyar. Initial stress produced in the periodontal membrane by orthodontic loads in the presence of varying loss of alveolar bone: a three-dimensional finite element analysis. Eur J Orthod 2002; 24(1):21-33.

12) Brian $W$ lee. Relationship between tooth movement rate and estimated pressure applied. J Dent Research 1965; 44:1053.

13) Cobo J, Sicilia A, Argüelles J, Suárez D, Vijande M. Initial stress induced in periodontal tissue with diverse degrees of bone loss by an orthodontic force: tridimensional analysis by means of the finite element method. Am J Orthod Dentofacial Orthop 1993; 104(5): 448-54.

\section{Source of Support: Nil, Conflict of Interest: None Declared}

